\title{
A EDUCAÇÃO PERMANENTE NO TREINAMENTO DO ENFERMEIRO DE CENTRO CIRÚRGICO: REVISÃO INTEGRATIVA
}

\author{
The permanent education in the training of nurses in the surgical center: integrative review
} La educación permanente en la formación de enfermeras en el centro quirúrgico: examen integrador

\author{
Mariângela Belmonte Ribeiro'
}

RESUMO: Objetivos: Identificar, na literatura, como é realizada a educação permanente do enfermeiro de Centro Cirúrgico (CC) e sugerir um roteiro de treinamento. Método: Revisão integrativa de artigos alojados na Biblioteca Virtual em Saúde (BVS) e no Google Acadêmico entre 2002 e 2015. Foram utilizados os descritores controlados: educação em enfermagem, educação continuada, capacitação em serviço e CC. Resultados: A busca permitiu a escolha de 14 artigos que abordaram 4 temas principais: a educação continuada ou permanente como importante desenvolvimento para a capacitação em relação aos processos e à tecnologia; o enfermeiro como educador e pesquisador; avaliação do ensino aprendizagem; e a educação a distância (EaD) como importante ferramenta para treinamento do enfermeiro de CC. Conclusão: Conclui-se que os estudos voltados para o treinamento do enfermeiro de CC são realizados na EAD; e foi apontada a importância do treinamento in loco seguindo um roteiro proposto.

Palavras-chave: Educação em enfermagem. Educação continuada. Capacitação em serviço. Centro Cirúrgico.

ABSTRACT: Objectives: To Identify in the literature how the permanent education of the nurses of the operating room is held and to suggest a training roadmap. Method: Integrative review of articles indexed in the Virtual Health Library (VHL) and Google Scholar between 2002 and 2015. The descriptors used were the following: education in nursing, continuing education, training and surgical center. Results: The search led to 14 articles covering 4 main themes: continuing or permanent education as an important development for training on processes and technology; the nurse as educator and researcher; evaluation of the teaching-learning process; and distance education as an important tool for surgical center nurse training. Conclusion: Studies focused on the training of surgical center nurses are performed by means of distance education and the importance of on-the-job training using a script was reinforced.

Keywords: Education, nursing. Education, continuing. Inservice training. Surgicenters.

RESUMEN: Objetivos: Identificar, en la literatura, como se lleva a cabo la educación permanente de la enfermera del centro quirúrgico y sugerir un itinerario formativo. Método: Revisión Integrativa de los artículos alojados en la Biblioteca Virtual de Salud (BVS) y Google Scholar entre 2002 y 2015. Se utilizaron los descriptores controlados: educación en enfermería, educación continua, formación y quirófano. Resultados: La búsqueda ha permitido la selección de 14 artículos que abordaron 4 temas principales: la continua o permanente educación como un desarrollo importante para la creación de capacidad en relación con los procesos y la tecnología; la enfermera como educador e investigador; evaluación de centros quirúrgicos; la enseñanza y el aprendizaje; y la educación a distancia como una herramienta importante para la formación de enfermeras centros quirúrgicos. Conclusión: Se concluye que los estudios se centraron en el centro de formación enfermera quirúrgica se llevan a cabo en la educación a distancia; y fue nombrado la importancia de la formación in situ siguiendo una hoja de ruta propuesta.

Palabras clave: Educación en enfermería. Educación continua. Capacitación en servicio. Centros quirúrgicos.

'Enfermeira. Mestre em Enfermagem pelo Programa de Mestrado Profissional do Centro Universitário São Camilo. Especialista em Centro Cirúrgico e Central de Material Esterilizado pela Universidade de São Paulo (USP). Enfermeira no Hospital Moriah - São Paulo (SP), Brasil. E-mails: mauribe@terra.com.br, mariangela.ribeiro@hospitalmoriah.com.br

Recebido: 28 nov. 2016 - Aprovado: 18 abr. 2017

DOI: $10.5327 / Z 1414-4425201700020007$ 


\section{INTRODUÇÃO}

Para fazer face às exigências do nosso tempo, é preciso repensar o processo de trabalho no Centro Cirúrgico (CC), visando a uma assistência integral voltada para a segurança do paciente com planejamento, educação e treinamento ${ }^{1}$.

Nessa mesma linha, com as novas exigências das organizações de saúde, a enfermagem também enfrenta transformações, necessitando ampliar seus conhecimentos continuamente ${ }^{2}$.

A educação em saúde é responsável pela transformação dos conhecimentos coletivos das pessoas envolvidas no processo de trabalho dentro da área da saúde, criando uma dinâmica no processo de fazer-se e refazer-se ${ }^{3}$.

O treinamento individualizado é apontado como uma proposta de educação em saúde, que possibilita o acompanhamento do novo colaborador antes de assumir suas funções ${ }^{4}$.

A educação na enfermagem tem a responsabilidade de capacitar a equipe em relação ao aperfeiçoamento das técnicas e das novas tecnologias ${ }^{5}$.

A transmissão do conhecimento pode ser realizada por meio de filmes, dinâmica de grupo, ambientes virtuais, programas computadorizados e ainda os meios verbais ${ }^{6}$.

Para o enfermeiro de CC, a educação a distância $(\mathrm{EaD})$ surge como ferramenta de treinamento, com a vantagem de ser realizada no próprio local de trabalho, sem afastar o colaborador por muito tempo, e de receber o conteúdo do treinamento por meio de vídeos e teleconferências ${ }^{7}$.

Considera-se que a revisão integrativa na temática de como é realizada a educação permanente no treinamento do enfermeiro de CC se faz necessária para que esse tipo de estudo possa contribuir para a melhoria da prática e assistência prestada, assim como para o ensino, a pesquisa e a área administrativa de atuação do enfermeiro de CC.

\section{OBJETIVOS}

Identificar na literatura como é realizada a educação permanente do enfermeiro de CC; e propor um roteiro de treinamento para o enfermeiro de CC.

\section{MÉTODO}

Trata-se de uma revisão integrativa sobre como é realizado o treinamento do enfermeiro de CC, tendo como referencial metodológico seis etapas: formulação do problema, estabelecimento dos critérios de inclusão e exclusão, levantamento de dados a serem extraídos dos textos, avaliação dos dados coletados, análise e interpretação dos dados, e apresentação dos resultados ${ }^{8}$. A questão que norteou este estudo foi "como é realizada, nas instituições, a educação permanente do enfermeiro de CC, diante das novas tecnologias e rotinas?”.

O levantamento de dados ocorreu nos meses de janeiro a junho de 2016. A Biblioteca Virtual em Saúde (BVS) foi escolhida por disponibilizar um grande conteúdo de material científico advindo das bases de dados referenciais nos campos da saúde, tais como: Literatura Latino-Americana de Ciências da Saúde da América Latina e do Caribe (LILACS), Literatura Internacional em Ciências da Saúde (MEDLINE), Biblioteca Cochrane, Scientific Electronic Library On-line (SciELO) e Base de Dados de Enfermagem (BDENF). Foram utilizados os descritores em ciências da saúde em português (DeCS) nas combinações: educação AND enfermeiro AND centro cirúrgico; educação continuada AND enfermeiro AND centro cirúrgico; e educação permanente AND enfermeiro AND centro cirúrgico.

Com a finalidade de ampliar a pesquisa, devido aos poucos artigos que foram encontrados na literatura envolvendo o treinamento do enfermeiro de CC, foi elaborada uma consulta no Google Acadêmico com as combinações: educação continuada e educação permanente; enfermeiro e centro cirúrgico.

Esse período alargado de 2002 a 2015 justificou-se pela escassa produção relacionada a artigos com foco no treinamento do enfermeiro de CC.

Foi realizada a análise dos títulos que continham na sua composição as palavras educação continuada ou permanente, pois muitos autores utilizam essas palavras como sinônimo; e, ainda, enfermagem, centro cirúrgico ou perioperatório, para a seleção inicial dos artigos.

Em seguida, os resumos dos artigos foram lidos e, após leitura, alguns estudos tinham a educação como tema, porém com enfoque em um treinamento específico que não se aplicava aos objetivos do trabalho, sendo, por isso, excluídos.

Foram selecionados os artigos nos idiomas português e inglês, os quais apresentassem informações a respeito de como é realizada a educação permanente ou continuada para o enfermeiro na unidade do CC, que dispunham de textos completos on-line, sendo eles de acesso livre ou não.

Foram incluídos artigos de enfermagem com foco em educação, que pudessem agregar no treinamento dos enfermeiros de CC, devido à escassez de trabalhos envolvendo a educação para o enfermeiro na área de CC. 
Foram excluídos os artigos que não tratavam da temática do foco central da pesquisa e os escritos em outras línguas que não o inglês.

Para a classificação dos níveis de evidências dos artigos, esses foram classificados em uma escala de 1 a 6 , da seguinte forma:

- nível 1 (C1): evidências resultantes da meta-análise de múltiplos estudos clínicos controlados e randomizados;

- nível 2 (C2): evidências obtidas em estudos individuais com delineamento experimental;

- nível 3 (C3): evidências de estudos quase-experimentais;

- nível 4 (C4): evidências de estudos descritivos (não experimentais) ou com abordagem qualitativa;

- nível 5 (C5): evidências provenientes de relatos de caso ou de experiência;

- nível 6 (C6): evidências baseadas em opiniões de especialistas 9 .

A classificação dos artigos é uma recomendação para qualquer estudo de revisão, pois enriquece e fortalece as conclusões em relação ao tema pesquisado.

Após a leitura na íntegra dos 14 artigos e avaliação dos dados extraídos de cada texto, foi elaborado um quadro com autores, nome da revista ou jornal de publicação, país de origem, tipo de estudo, resultados e nível de evidência.

A busca forneceu um total de 357 artigos com as combinações mostradas no fluxograma (Figura 1).

\section{RESULTADOS}

O Quadro 1 apresenta as principais características dos estudos incluídos na revisão integrativa

Após a leitura dos 62 resumos, foram selecionados 18 artigos, os quais foram lidos na íntegra; e os estudos passaram por uma avaliação mediante os demais critérios de inclusão. Quatro artigos foram excluídos: dois não respondiam à pergunta da pesquisa e os outros dois tinham dados insuficientes em relação aos objetivos da pesquisa, sendo 14 os artigos escolhidos.

Sobre suas características, 13 artigos foram publicados em português e 1 em inglês. $\mathrm{O}$ ano de publicação variou entre 2002 e 2015. Para a apresentação dos resultados, foi organizado um quadro com os seguintes dados: autores, jornais ou revistas, origem, tipos de estudo, sendo nove estudos descritivos (nível de

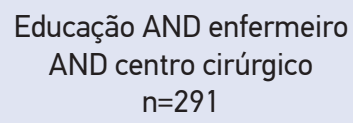

Educação continuada AND enfermeiro AND centro cirúrgico $\mathrm{n}=53$
Educação permanente AND enfermeiro AND centro cirúrgico $\mathrm{n}=13$

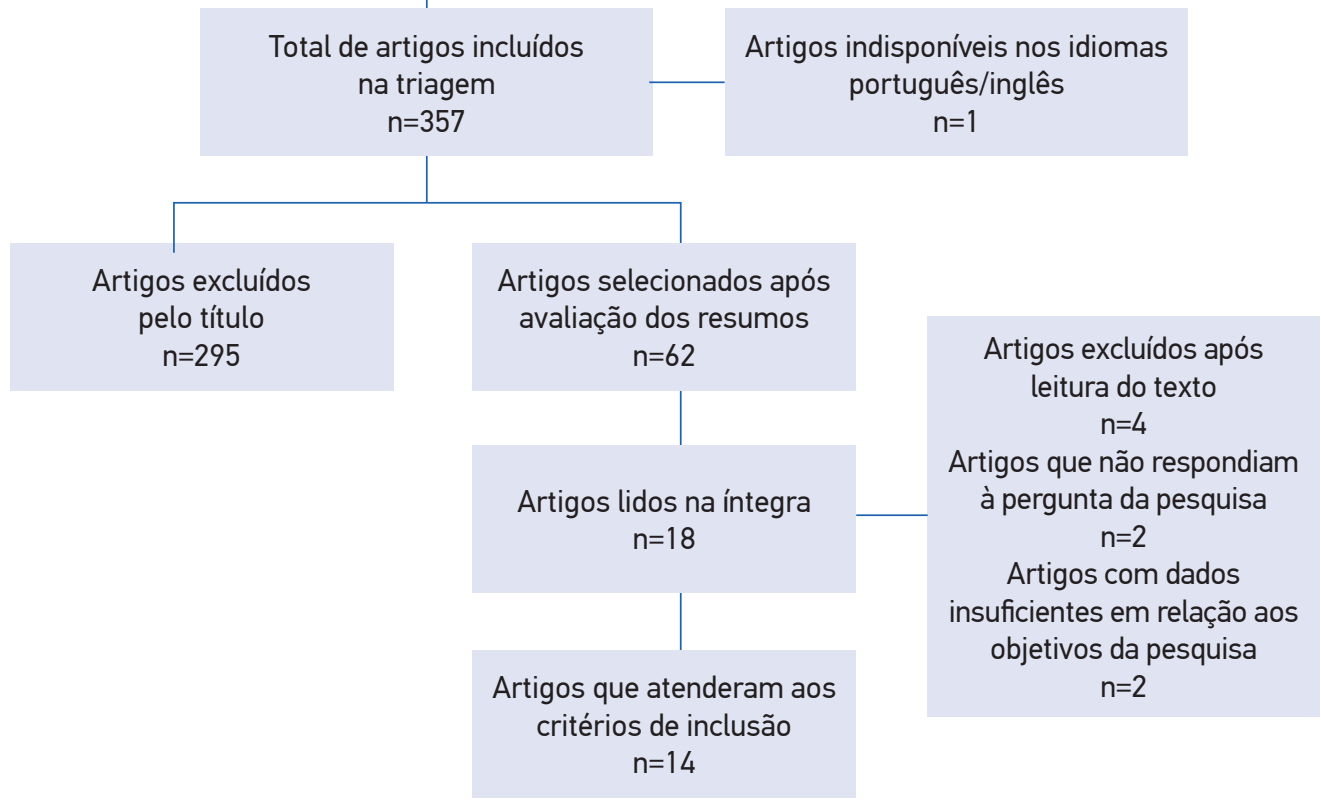

Figura 1. Fluxograma do processo de levantamento de artigos científicos. 
Quadro 1. Síntese dos estudos encontrados em relação aos treinamentos para a enfermagem e o treinamento das enfermeiras de Centro Cirúrgico.

\begin{tabular}{|c|c|c|c|c|c|}
\hline Autores & $\begin{array}{l}\text { Revistas/ } \\
\text { jornais }\end{array}$ & Origem & $\begin{array}{l}\text { Tipo de } \\
\text { estudo }\end{array}$ & Resultados & Nível \\
\hline $\begin{array}{l}\text { Pereira et al. }{ }^{1} \\
(2013)\end{array}$ & $\begin{array}{l}\text { Revista de } \\
\text { Pesquisa } \\
\text { Cuidado é } \\
\text { fundamental } \\
\text { Online }\end{array}$ & Brasil & $\begin{array}{l}\text { Qualitativa, } \\
\text { descritiva e } \\
\text { exploratória }\end{array}$ & $\begin{array}{l}\text { Foram classificados em cinco categorias que apontam, no processo } \\
\text { de trabalho da Enfermagem: as múltiplas compreensões sobre } \\
\text { o processo gerencial; as implicações das relações de poder; } \\
\text { a compreensão do mesmo como processo de enfermagem, a } \\
\text { educação permanente e a tecnologia vista como uma necessidade } \\
\text { para o desenvolvimento do referido processo }\end{array}$ & $\mathrm{C} 4$ \\
\hline $\begin{array}{l}\text { Bezerra² } \\
(2012)\end{array}$ & $\begin{array}{l}\text { Revista } \\
\text { Eletrônica de } \\
\text { Enfermagem }\end{array}$ & Brasil & $\begin{array}{l}\text { Descritivo } \\
\text { exploratório }\end{array}$ & $\begin{array}{l}\text { Os enfermeiros acreditam na educação continuada e a maioria } \\
\text { desenvolve essa atividade anualmente; as estratégias de ensino- } \\
\text { aprendizagem predominantes são: exposição dialogada e } \\
\text { problematização de casos; os programas englobam habilidades } \\
\text { técnicas e comportamentais e a avaliação é feita por meio de auditoria }\end{array}$ & C4 \\
\hline $\begin{array}{l}\text { Silva et al. }{ }^{3} \\
(2010)\end{array}$ & $\begin{array}{l}\text { Revista } \\
\text { Gaúcha de } \\
\text { Enfermagem }\end{array}$ & Brasil & $\begin{array}{l}\text { Reflexão } \\
\text { teórica }\end{array}$ & $\begin{array}{l}\text { Tal articulação apresenta uma concepção educativa em prol da } \\
\text { conscientização dos trabalhadores sobre as contribuições nas } \\
\text { diferentes formas de receber e exercer a educação permanente em } \\
\text { saúde e no trabalho da Enfermagem }\end{array}$ & $\mathrm{C} 5$ \\
\hline $\begin{array}{l}\text { Siqueira e } \\
\text { Kurcgant }{ }^{4} \\
(2005)\end{array}$ & $\begin{array}{l}\text { Revista de } \\
\text { Enfermagem } \\
\text { da USP }\end{array}$ & Brasil & $\begin{array}{l}\text { Relato de } \\
\text { pesquisa }\end{array}$ & $\begin{array}{l}\text { O programa vem apresentando bons resultados em relação à } \\
\text { individualização do treinamento e participação dos enfermeiros da } \\
\text { instituição }\end{array}$ & $\mathrm{C} 5$ \\
\hline $\begin{array}{l}\text { Puggina } \\
\text { et al. } \\
\text { (2015) }\end{array}$ & $\begin{array}{c}\text { Revista Espaço } \\
\text { para a Saúde }\end{array}$ & Brasil & $\begin{array}{l}\text { Descritivo } \\
\text { exploratório } \\
\text { com } \\
\text { abordagem } \\
\text { qualitativa }\end{array}$ & $\begin{array}{l}\text { Destacam-se a dificuldade dos profissionais em participar das } \\
\text { atividades por falta de pessoas para substituí-los, a falta de } \\
\text { otimização do tempo e de interesse pessoal. } \\
\text { Quanto às estratégias está o planejamento das ações junto às } \\
\text { equipes. Enfatiza-se que a educação permanente em saúde } \\
\text { precisa ser entendida como um instrumento capaz de promover } \\
\text { o aprimoramento dos trabalhadores e mudanças construtivas no } \\
\text { processo de trabalho }\end{array}$ & $\mathrm{C} 4$ \\
\hline $\begin{array}{l}\text { Oliveira6 } \\
(2007)\end{array}$ & $\begin{array}{l}\text { Revista } \\
\text { Brasileira de } \\
\text { Enfermagem }\end{array}$ & Brasil & Descritivo & $\begin{array}{l}\text { Aponta que a educação permanente em saúde é uma das estratégias } \\
\text { para a formação do profissional através de trabalhos coletivos entre } \\
\text { os docentes. Como alternativa a educação a distância possibilita } \\
\text { construir um novo estilo na formação }\end{array}$ & $\mathrm{C} 4$ \\
\hline $\begin{array}{l}\text { Castro e } \\
\text { Takahashi14 } \\
\text { (2008) }\end{array}$ & $\begin{array}{l}\text { Revista de } \\
\text { Enfermagem } \\
\text { da USP }\end{array}$ & Brasil & $\begin{array}{c}\text { Qualitativa } \\
\text { na vertente } \\
\text { da análise de } \\
\text { conteúdo }\end{array}$ & $\begin{array}{l}\text { Os resultados mostraram as posições dos enfermeiros em três } \\
\text { categorias distintas: (1) dificuldades percebidas no processo de } \\
\text { avaliação da aprendizagem em relação à disponibilidade de tempo; } \\
\text { sentimentos negativos quanto à avaliação; e despreocupação } \\
\text { com os resultados dos treinamentos são os desafios a serem } \\
\text { trabalhados no dia a dia; (2) metodologia desenvolvida no processo } \\
\text { de avaliação da aprendizagem devendo considerar diferentes ritmos } \\
\text { de aprendizado, sua experiência e história de vida e conhecimentos } \\
\text { anteriores; (3) avaliação do processo de ensino-aprendizagem como } \\
\text { um indicador preciso das ações passadas e controle da qualidade do } \\
\text { ensino adotado no treinamento }\end{array}$ & $\mathrm{C} 4$ \\
\hline $\begin{array}{l}\text { Silva et al. }{ }^{15} \\
(2008)\end{array}$ & Mundo Saúde & Brasil & $\begin{array}{l}\text { Descritivo } \\
\text { exploratório }\end{array}$ & $\begin{array}{l}\text { Espera-se que possa contribuir para melhorar o respectivo } \\
\text { desempenho e desenvolvimento profissional e também para } \\
\text { melhorar a autoestima dos enfermeiros assistenciais exercendo } \\
\text { atividades educacionais, não só na própria unidade, mas } \\
\text { eventualmente em outras promovidas pela educação continuada }\end{array}$ & $\mathrm{C} 4$ \\
\hline $\begin{array}{l}\text { Silva e } \\
\text { Sieffert } \\
\text { (2009) }\end{array}$ & $\begin{array}{c}\text { Revista } \\
\text { Brasileira de } \\
\text { Enfermagem }\end{array}$ & Brasil & $\begin{array}{l}\text { Estudo de } \\
\text { caso } \\
\text { prospectiva } \\
\text { quali- } \\
\text { quantitativa }\end{array}$ & $\begin{array}{l}\text { Sugeriram reflexões sobre o desenvolvimento dos processos } \\
\text { educativos em Enfermagem, identificando desafios a superar pelo } \\
\text { grupo. Para fazer da educação dos profissionais de Enfermagem um } \\
\text { processo permanente, deve-se considerar o trabalho diário como } \\
\text { eixo do processo educativo, fonte de conhecimento e objeto de } \\
\text { transformação que privilegia participação coletiva e interdisciplinar }\end{array}$ & $\mathrm{C} 5$ \\
\hline
\end{tabular}


Quadro 1. Continuation.

\begin{tabular}{|c|c|c|c|c|c|}
\hline Autores & $\begin{array}{l}\text { Revistas/ } \\
\text { jornais }\end{array}$ & Origem & $\begin{array}{l}\text { Tipo de } \\
\text { estudo }\end{array}$ & Resultados & Nível \\
\hline $\begin{array}{l}\text { Galvão et al. }{ }^{17} \\
(2002)\end{array}$ & $\begin{array}{l}\text { Revista Latino- } \\
\text { Americana de } \\
\text { Enfermagem }\end{array}$ & Brasil & $\begin{array}{l}\text { Artigo de } \\
\text { revisão }\end{array}$ & $\begin{array}{l}\text { A prática baseada em evidências; conceitos gerais, importância e } \\
\text { barreiras para sua implementação na prática profissional com a finalidade } \\
\text { de incentivar o enfermeiro cirúrgico a buscar conhecimento científico por } \\
\text { meio do desenvolvimento de pesquisas e utilização de seus resultados. }\end{array}$ & $\mathrm{C} 4$ \\
\hline $\begin{array}{l}\text { Sena et al. }{ }^{18} \\
(2013)\end{array}$ & $\begin{array}{l}\text { Revista } \\
\text { Gaúcha de } \\
\text { Enfermagem }\end{array}$ & Brasil & $\begin{array}{l}\text { Descritivo } \\
\text { com } \\
\text { abordagem } \\
\text { qualitativa }\end{array}$ & $\begin{array}{l}\text { Grande parte dos cuidados se refere à orientação do paciente no } \\
\text { pré-operatório. Os cuidados foram direcionados aos aspectos físicos } \\
\text { em detrimento do psicológico, em discordância com a metodologia } \\
\text { assistencial adotada no hospital, sustentada pela Teoria das } \\
\text { Necessidades Humanas Básicas }\end{array}$ & $\mathrm{C} 4$ \\
\hline $\begin{array}{l}\text { Oliveira e } \\
\text { Servo } \\
(2004)\end{array}$ & $\begin{array}{c}\text { Revista } \\
\text { Sitientibus }\end{array}$ & Brasil & $\begin{array}{l}\text { Artigo de } \\
\text { revisão }\end{array}$ & $\begin{array}{l}\text { A educação a distância na apresentação dos limites e as possibilidades, } \\
\text { como estratégia de educação permanente do enfermeiro de CC } \\
\text { diante das novas tecnologias, capacitação dos profissionais no local } \\
\text { de trabalho, alcance de um grande número de pessoas e de grupos, } \\
\text { processos continuados de acesso ao conhecimento }\end{array}$ & C4 \\
\hline $\begin{array}{l}\text { Ortiz et al. }{ }^{10} \\
(2008)\end{array}$ & $\begin{array}{l}\text { Revista } \\
\text { Cogitare de } \\
\text { Enfermagem }\end{array}$ & Brasil & $\begin{array}{l}\text { Descritiva } \\
\text { com } \\
\text { abordagem } \\
\text { quantitativa }\end{array}$ & $\begin{array}{l}\text { Os resultados mostraram que a maioria (59\%) tinha título de } \\
\text { especialista e trabalhavam há mais de } 10 \text { anos na assistência } \\
\text { perioperatória. Observou-se que } 88 \% \text { possuíam computador em } \\
\text { casa e } 100 \% \text { deles tinham acesso à internet, no entanto, apenas 35\% } \\
\text { a utilizavam. Quanto à experiência com educação a distância, } 53 \% \\
\text { disseram não ter nenhuma experiência. } \\
\text { A maioria dos participantes ( } 88 \% \text { ) interessou-se na abertura de } \\
\text { cursos de educação a distância }\end{array}$ & C4 \\
\hline $\begin{array}{l}\text { Vigeant } \\
\text { et al. }{ }^{19} \\
(2008)\end{array}$ & Journal Nurses & Inglês & $\begin{array}{l}\text { Artigo de } \\
\text { revisão }\end{array}$ & $\begin{array}{l}\text { A utilização do vídeo no treinamento pode ser classificado em três } \\
\text { categorias: o uso do vídeo para demonstrar o conteúdo; o uso do } \\
\text { vídeo para autoanálise e a integração do vídeo em programas de } \\
\text { ensino multimídia }\end{array}$ & C4 \\
\hline
\end{tabular}

evidência C4), um de reflexão (nível de evidência C5), um relato (nível de evidência C5), dois de revisão (nível de evidência C4) e um estudo de caso (nível de evidência C5) ${ }^{9}$.

O ano com maior número de publicações (três) foi 2008 , seguido dos anos de 2012 e 2007, com duas publicações cada. As outras ocorreram entre os anos de 2002 e 2015.

Com base na análise crítica dos artigos foram identificadas quatro categorias temáticas em relação à educação para a Enfermagem e para os enfermeiros de CC: a educação continuada ou permanente como importante desenvolvimento para a capacitação em relação aos processos e à tecnologia; o enfermeiro como educador e pesquisador; avaliação do ensino aprendizagem; e a EaD como importante ferramenta para treinamento do enfermeiro de CC.

Em um estudo com 17 enfermeiros que trabalham na assistência perioperatória, $88 \%$ dos participantes mostraram interesse em participar de um curso de EaD, fazendo sugestões de temas e tendo a possibilidades de conciliar o tempo e agregar novos conhecimentos ${ }^{10}$.

A pesquisa demonstrou uma escassez de trabalhos a respeito de como é realizado o treinamento dos enfermeiros de CC. Baseado no processo de trabalho da enfermagem no modelo de Sanna ${ }^{11}$, um roteiro foi desenvolvido com duas etapas: assistir e participar na assistência perioperatória, assim como ensinar, pesquisar e administrar para desenvolver a equipe de enfermagem, voltado para o treinamento do enfermeiro de CC.

\section{Assistir e participar}

- Conhecer o fluxograma do CC e da sala de recuperação anestésica, assim como a localização e o funcionamento das áreas de apoio (farmácia, engenharia clínica, central de material esterilizado, laboratório de anatomia patológica e análise clínica, sistema de informática).

- Conhecer os procedimentos operacionais padrão (POPs) e como obter acesso.

- Receber o paciente no CC, com a conferência do nome completo e da data de nascimento.

- Confirmar os termos: cirúrgico, anestésico e de transfusão sanguínea, quando necessário.

- Checar a demarcação do sítio cirúrgico, quando aplicável, na importância do checklist de cirurgia segura ${ }^{12}$. 
- Conhecer a importância da avaliação pré-anestésica de acordo com o perfil dos pacientes atendidos pela instituição.

- Montar dos kits para a anestesia e a monitorização.

- Auxiliar o ato anestésico, com noções referentes aos tipos de anestesias; ações das drogas anestésicas, reações adversas, complicações e o controle da dor, o qual pode ser elaborado em duas partes: teórica (com vídeos e aulas) e prática.

- Montar os diferentes tipos de monitorizações invasivas.

- Atender na sala operatória (SO) em caso de parada cardiorrespiratória.

- Conhecer a rotina de montagem da SO, assim como o fluxo de solicitação do kit cirúrgico na farmácia e dos instrumentais no centro de material e esterilização, e os equipamentos em $\mathrm{SO}$ e como esses devem ser testados.

- Conhecer a responsabilidade do técnico de enfermagem e suas atividades como circulante durante o procedimento cirúrgico.

- Encaminhar o paciente para a sala de recuperação anestésica ou unidade de terapia intensiva (UTI).

- Passar noções da importância do controle de infecção dentro da sala operatória, uso de barreiras e procedimentos de antissepsia. As cirurgias não ocorrem em condições absolutamente estéreis. Sempre há a possibilidade de penetração de microrganismos, sejam de fontes exógenas (ar ambiente, profissionais, equipamentos etc.) ou de fontes endógenas (do próprio paciente) ${ }^{13}$.

- Preencher o checklist de cirurgia segura com a equipe multiprofissional, com enfoque na segurança do paciente.

- Conhecer as posições cirúrgicas e os principais tipos de posicionamentos cirúrgicos e acessórios utilizados para proteção (posicionadores).

- Realizar a anotação de enfermagem em SO, com registro de todo o período operatório com detalhes da anestesia, do posicionamento, do próprio ato cirúrgico, com descrição de materiais especiais e consignados, para evitar as glosas dos convênios.

- No caso de intercorrências, devem relatar os detalhes da assistência prestada pela equipe multiprofissional.

- Conhecer o funcionamento dos equipamentos e sua utilização para cada procedimento cirúrgico.

- Treinar as habilidades para utilizar o sistema de informática da instituição.

- Conhecer as rotinas de admissão dos cuidados prestados na assistência ao paciente na sala de recuperação.

\section{Ensino, pesquisa e administração}

- Treinamento e reciclagem das rotinas com a equipe e com os novos colaboradores.

- Revisão e elaboração de novos POPs do setor.

- Dimensionamento da equipe, assim como confecção das escalas de folgas, férias e atividades diárias dos colaboradores.

- Conhecer o fluxo do agendamento cirúrgico e a parte operacional da rotina diária do mapa cirúrgico, assim como a distribuição dos procedimentos nas salas operatórias.

- Checar a solicitação mediante o mapa cirúrgico com a finalidade de prever e prover materiais e equipamentos para cada procedimento.

- Garantir a adesão da equipe multiprofissional do checklist de cirurgia segura ${ }^{12}$.

- Conhecer os indicadores e participar para que as metas sejam alcançadas.

- Receber conhecimentos referentes a acreditações de saúde.

- Desenvolver trabalhos para a diminuição de custos no CC, evitando, assim, o desperdício com a abertura dos materiais.

- Participar da elaboração de trabalhos científicos para divulgação da pesquisa na Enfermagem.

\section{DISCUSSÃO}

A revisão da literatura identificou a maioria dos artigos como estudos descritivos e relatos de casos. Com base no referencial metodológico adotado, essas categorias de estudo se enquadram nos níveis de evidência C4 e C5.

Esse resultado demonstrou que estudos mais robustos, como estudos de coorte e revisões sistemáticas com meta-análises ${ }^{9}$, precisam ser desenvolvidos para melhorar o número de evidências científicas sobre a temática do estudo.

Apesar da fragilidade dos estudos, esses possuem conceitos e informações importantes que respondem à questão norteadora da revisão.

Os principais temas identificados na análise crítica dos artigos e suas implicações são apresentados e discutidos na sequência.

\section{Formação como pesquisador e educador}

A importância da aplicação do ensino e da aprendizagem dentro do ambiente de trabalho vem despontando como uma ferramenta de educação dentro das organizações de saúde ${ }^{14}$. 
O desenvolvimento da equipe de Enfermagem é de responsabilidade do enfermeiro da educação continuada, que conta com o apoio de outros enfermeiros da instituição; no entanto, esse enfermeiro deve ter formação compatível com a de um educador e compartilhar esses conhecimentos com toda a equipe de Enfermagem ${ }^{15}$.

A educação continuada em Enfermagem, como proposta metodológica, é considerada importante. Sendo assim, os conteúdos desenvolvidos devem ser voltados para a realidade do dia a dia, levando em consideração o cotidiano do trabalho, as necessidades do setor e da instituição e a evolução tecnológica ${ }^{16,17}$.

A implementação da prática baseada em evidências na Enfermagem perioperatória contribui para a melhoria da assistência prestada e para a diminuição de $\operatorname{custos}^{17}$.

No CC, o enfermeiro tem a responsabilidade de garantir a qualidade da assistência prestada, visando à diminuição de danos ao paciente, assim como ser formador de opiniões e treinar a sua equipe ${ }^{18}$.

\section{Educação e tecnologia}

A EaD, como estratégia da educação permanente do enfermeiro em CC, é importante ferramenta para facilitar o acesso ao conhecimento, no qual o aprendizado ocorre na própria unidade de trabalho, por meio de teleconferência ou videoconferência ${ }^{7}$.

Para os enfermeiros de CC, a EaD apresenta alguns pontos negativos que podem vir a comprometer o treinamento, como a agenda cirúrgica intensa, dificultando a saída do enfermeiro do bloco operatório para o treinamento no computador, além de dificuldades em relação à utilização da mídia ${ }^{7-10}$.

\section{Treinamentos}

Com a tecnologia cada vez mais presente nos procedimentos cirúrgicos, existe uma preocupação em preparar o enfermeiro do bloco operatório para prestar uma assistência humanizada ao paciente cirúrgico ${ }^{1}$.

A junção de recursos didáticos, como filmes, dinâmica grupal, manequins educativos e situações simuladas para discussões e avaliações dos procedimentos, demostrou um maior entrosamento da equipe nos treinamentos, com participação efetiva do enfermeiro monitor e do recém-contratado ${ }^{4}$.

Uma outra mídia de treinamento para os enfermeiros de CC é o vídeo, que por meio da simulação de casos que acontecem na rotina diária estimula debates dos casos associados com as práticas teóricas ${ }^{19}$.
O estudo realizado na unidade de internação, no qual o enfermeiro monitor acompanha o enfermeiro recém-admitido durante o período de treinamento, foi utilizado como base para a construção do roteiro ${ }^{4}$ de treinamento do enfermeiro de CC.

\section{Perfil do enfermeiro educador}

O instrutor, como planejador e executor do processo, deve estabelecer relações concretas entre teoria, prática e realidade; sendo o CC um setor de alta complexidade, o enfermeiro educador deve ter conhecimento e domínio das rotinas, tanto assistenciais como administrativas, para treinar os novos enfermeiros e a equipe de Enfermagem ${ }^{10,16}$.

O enfermeiro de CC, segundo a Associação Brasileira de Enfermeiros de Centro Cirúrgico, Recuperação Anestésica e Centro de Material e Esterilização (SOBECC), é o profissional habilitado para gerenciar as necessidades que envolvem o ato anestésico-cirúrgico em todas as suas etapas. É recomendável que o enfermeiro seja especialista na área de conhecimento em que atua ${ }^{20}$.

\section{Avaliação do processo e aprendizado}

A avaliação do processo de ensino-aprendizagem mostra resultados reais por meio de instrumentos confiáveis, como os pontos falhos, as dificuldades e como superar essas falhas, melhorando, assim, tal articualção ${ }^{14}$.

A técnica da utilização do vídeo como autoanálise é importante ferramenta para análise e autoconhecimento ${ }^{19}$.

\section{Limitações}

A pesquisa demonstrou um número reduzido de artigos e as publicações trazem referenciais didáticos baseados em tipos de estudos com níveis de evidência fraca (C4 e C5).

\section{CONCLUSÃO}

Os dois trabalhos voltados para a educação do enfermeiro de CC mostraram a EaD como ferramenta de treinamento, e um artigo apontou o uso de vídeo como instrumento para educação.

Um trabalho realizado na unidade de internação aponta a importância do treinamento para os enfermeiros de CC 
no local de trabalho, dentro do setor, devido à complexidade cada vez maior dos equipamentos.

Com base neste artigo, um roteiro foi apresentado para o enfermeiro de CC, levando em conta as partes assistencial, educacional, de pesquisa e administrativa.
A avaliação, por facilitar a interação entre educador e colaborador, possibilitar colocações a respeito do conteúdo do treinamento e permitir melhoras no processo de ensino -aprendizagem, é de grande importância para o retorno do aprendizado e foi citada em vários artigos da amostra.

\section{REFERÊNCIAS}

1. Pereira FCC, Bonfada D, Valença CN, Miranda FAN, Germano RM [Internet]. Compressão de enfermeiros de centro cirúrgico a respeito do seu processo de trabalho. Rev Pesq Cuid Fundam. 2013 [acesso 20 mar. 2016];5(1):3251-8. Disponível em: http://www.seer.unirio. br/index.php/cuidadofundamental/article/view/1879/pdf_675

2. Bezerra ALQ. O contexto da educação continuada em enfermagem na visão dos gerentes de enfermagem e dos enfermeiros de educação continuada. Rev Eletron Enferm. 2002 [acesso 13 mar. 2016];4(1):66. Disponível em: https://www.revistas.ufg.br/fen/article/view/734/794

3. Silva LAA, Ferraz F, Lino MM, Backes VMS, Schmidt SMS [Internet]. Educação permanente em saúde e no trabalho de enfermagem: perspectiva de uma práxis transformadora. Rev Gaúcha Enferm. 2010 [acesso 13 abr. 2016];31(3):557-61. Disponível em: http://dx.doi. org/10.1590/S1983-14472010000300021

4. Siqueira ILCP, Kurcgant $P$ [Internet]. Estratégia de capacitação de enfermeiros recém-admitidos em unidades de internação geral. Rev Enferm USP. 2005 [acesso 12 maio 2016];39(3):231-51. Disponível em: http://dx.doi.org/10.1590/S0080-62342005000300002

5. Puggina CC, Amestoy SC, Fernandes HN, Carvalho LA, Báo ACP, Alves FO [Internet]. Educação Permanente em Saúde: instrumento de transformação do trabalho de enfermeiros. Rev Espaço Saúde. 2015 [acesso 18 mar. 2016];16(4):87-97. Disponivel em: http://www.uel. $\mathrm{br} /$ revistas/uel/index.php/espacoparasaude/article/view/22580/11

6. Oliveira MAN [Internet]. Educação à distância como estratégia para a educação permanente: possibilidades e desafios. Rev Bras Enferm. 2007 [acesso 13 abr. 2016];60(5):585-9. Disponível em: http://www. scielo.br/pdf/reben/v60n5/v60n5a19

7. Oliveira MAN, Servo MLS [Internet]. A educação à distância como estratégia da educação permanente do enfermeiro em centro cirúrgico frente as novas tecnologias. Rev Sitientibus. 2004 [acesso 5 mar. 2015];(30):9-20. Disponível em: http://www2.uefs.br/sitientibus/ pdf/30/educacao_a_distancia_como_estrategia.pdf

8. Mendes KDS, Silveira RCCP, Galvão CM [Internet]. Revisão Integrativa: Método de pesquisa para a incorporação de evidências na saúde e na enfermagem. Rev Texto Contexto Enferm. 2008 [acesso 5 mar. 2016];17(4):758-64. Disponível em: http://producao.usp.br/handle/BDPI/3509

9. Stetler CB, Morsi D, Rucki S, Broughton S, Corrigan B, Fitzgerald J, et al. Utilization-focused integrative reviews in a nursing service. Appl Nurs Res. 1998;11(4):195-206.

10. Ortiz MCL, Ribeiro RP, Garanhani ML [Internet]. Educação à distância: uma ferramenta para a educação permanente de enfermeiros que trabalham com assistência perioperatória. Rev Cogitare Enferm. 2008 [acesso 8 jan. 2016];13(4):558-65. Disponivel em: http://revistas.ufpr. $\mathrm{br} /$ cogitare/article/view/13116/8874

11. Sanna MC [Internet]. Os processos de trabalho em enfermagem. Rev Bras Enferm. 2007 [acesso 31 mar. 2017];60(2):221-4. Disponível em: https://dx.doi.org/10.1590/S0034-71672007000200018

12. Organização Mundial da Saúde [Internet]. Segundo desafio global para a segurança do paciente: cirurgias seguras salvam vidas. Rio de Janeiro: Organização Pan-Americana da Saúde/Ministério da Saúde/Agência Nacional de Vigilância Sanitária; 2009 [acesso fev. 2016]. Disponível em: http://bvsms.saude.gov.br/bvs/publicacoes/ seguranca_paciente_cirurgia_salva_manual.pdf

13. Lacerda RA. Controle de infecção em centro cirúrgico fatos, mitos e controvérsias. São Paulo: Atheneu; 2003.

14. Castro LC, Takahashi RT [Internet]. Percepção dos enfermeiros sobre a avaliação da aprendizagem nos treinamentos desenvolvidos em um hospital de São Paulo. Rev Enferm USP. 2008 [acesso 10 fev. 2016];42(2):305-11. Disponível em: http://dx.doi.org/10.1590/ S0080-62342008000200014

15. Silva MF, Conceição FA, Leite MMJ [Internet]. Educação continuada: um levantamento de necessidades da equipe de enfermagem. Mundo Saúde. 2008 [acesso 15 jan. 2016];32(1):47-55. Disponível em: http:// romeukreutz.com/sirio/wp-content/uploads/2016/10/07-01.pdf

16. Silva GM, Seiffert OM [Internet]. Educação continuada em enfermagem: uma proposta metodológica. Rev Bras Enferm. 2009 [acesso 8 mar. 2016];62(3):362-5. Disponível em: http://dx.doi.org/10.1590/ S0034-71672009000300005

17. Galvão CM, Sawada NO, Rossi LA [Internet]. A prática baseada em evidências: considerações teóricas para sua implementação na enfermagem peri-operatória. Rev Latino-Am Enferm. 2002 [acesso 8 jan. 2016];10(5):690-5. Disponível em: http://dx.doi.org/10.1590/ S0104-11692002000500010

18. Sena AC, Nascimento ERP, Maia ARCR [Internet]. Prática do enfermeiro no cuidado ao paciente no pré-operatório imediato de cirurgia eletiva. Rev Gaúcha Enferm. 2013 [acesso 22 mar. 2017];34(3):132-7. Disponível em: https://dx.doi.org/10.1590/S1983-14472013000300017

19. Vigeant $D$, Lefebvre H, Reidy M. The use of video as a pedagogic tool for the training of perioperative nurses: a literature review. J Nurs. 2008;26(1):17-20.

20. Associação Brasileira de Enfermeiros de Centro Cirúrgico, Recuperação Anestésica e Centro de Material e Esterilização. Práticas recomendadas. $4^{\mathrm{a}}$ ed. São Paulo: SOBECC; 2009. 